\title{
A STUDY OF THE RECURRENCE RATES IN PATIENTS WITH CARCINOMA ANORECTUM UNDERGOING ABDOMINOPERINEAL RESECTION
}

\author{
Hardeep Singh Gill1 ${ }^{1}$ Puneet Jain², Anantbir Singh³, Satish Jain ${ }^{4}$ \\ ${ }_{1}^{1}$ Associate Professor, Department of General Surgery, Gian Sagar Medical College and Hospital, Banur, Punjab. \\ ${ }^{2}$ Assistant Professor, Department of General Surgery, Gian Sagar Medical College and Hospital, Banur, Punjab. \\ ${ }^{3}$ Post-Graduation Resident, Department of General Surgery, Gian Sagar Medical College and Hospital, Banur, Punjab. \\ ${ }^{4}$ Formerly Chief of Surgery \& Surgical Oncology, Mohan Dai Oswal Cancer Treatment and Research Foundation, Ludhiana, Punjab.
}

ABSTRACT: BACKGROUND: Cancer of colon and rectum is the most common cancer of the gastrointestinal tract. The rates of colorectal cancer in our country are not as high as those seen in the west, but trends require careful observation.

AIMS: In the present study, we have done a retrospective as well as prospective study of patients with carcinoma anorectum undergoing abdominoperineal resection with special emphasis on the recurrence rates, that is local recurrence as well as distant metastasis in the followup of these patients.

MATERIALS AND METHODS: 75 patients operated for APR were studied retrospectively and 25 patients operated for the same were studied prospectively.

RESULTS AND CONCLUSION: It was concluded that abdomino-perineal resection remains the 'Gold Standard' for low lying (5cm from anal verge) advanced carcinoma anorectum, but local disease recurrence is quite common following APR and distant metastases are also seen, most commonly to the liver and lungs.

KEYWORDS: Carcinoma Anorectum, Abdominoperineal Resection, Colon Cancer, Rectal Cancer, CEA.

HOW TO CITE THIS ARTICLE: Hardeep Singh Gill, Puneet Jain, Anantbir Singh, Satish Jain. "A Study of the Recurrence rates in Patients with Carcinoma Anorectum undergoing Abdominoperineal Resection." Journal of Evolution of Medical and Dental Sciences 2015; Vol. 4, Issue 94, November 23; Page: 15935-15942, DOI: 10.14260/jemds/2015/2321.

INTRODUCTION: Unlike in most parts of the world, age adjusted rates of cancer of rectum in Indian registries is higher than that of colon cancer in either sex and therefore assumes importance. Age adjusted rates of rectal cancer varied from $1.5 \%-3.3 \%$ in our country. There were 64 new cases of rectal cancer reported in our hospital in one year, accounting for $2.3 \%$ of all cancers. In our hospital, rectal cancer is more common than colon cancer.

Newer imaging modalities include Positron Emission Tomograpy (PET) scanning, which is a minimally invasive metabolic imaging modality using radiolabeled ligands. FDGPET scanning is superior to other scanning techniques for demonstrating multifocal liver metastasis and for presence of additional extrahepatic disease. FDG-PET scanning can also detect local recurrence at an earlier stage in colorectal cancer and can aid the decision making process regarding further management. CEA (Carcinoembryonic Antigen), which was first described by Gold and Freedman has been widely used for colorectal cancer staging and for prediction of survival and recurrence after surgery. Levels of CEA have been found to increase with more advanced tumor stage and poorly differentiated tumor grade and it is recommended as monitoring tool for patients treated with curative intent during their followup.

Financial or Other, Competing Interest: None.

Submission 31-10-2015, Peer Review 02-11-2015,

Acceptance 13-11-2015, Published 21-11-2015.

Corresponding Author:

Dr. Hardeep Singh Gill,

Associate Professor, Department of General Surgery,

Gian Sagar Medical College and Hospital,

Banur, Rajpura-140401,

Punjab, India.

E-mail: hardeepgill77@gmail.com

DOI:10.14260/jemds/2015/2321.
Total mesorectal excision, also called complete circumferential mesorectal excision has become the standard of care for mobile rectal cancers and as a result of its greater use 5-year survival rates have risen from $45 \%$ to $50 \%-75 \%$, local recurrence rates have declined from $30 \%$ to $5-8 \%$.

CARCINOMA ANAL CANAL: Carcinoma of Anal Canal is about one-tenth as common as rectal cancer and accounts for $1.5 \%$ of all the digestive systems cancer.

Epidermoid (Squamous Cell) carcinoma is the most common histological variant and represents about 75\%-80\% of anal cancer cases; somewhat less common is Basaloid Transitional cell (Cloacogenic) carcinoma. The difference between the two is only histological as their treatment and survival is similar. Rare types are adenocarcinoma (Originating from Anal glands) and melanoma.

The etiology of anal carcinoma can be summed up as a multifactorial interaction between environmental factors, Human Papilloma Virus Infection (HPV) and immune status.

\section{The risk factors for anal carcinoma include:}

- HPV infection (anogenital warts),

- H/O sexually transmitted disease,

- H/O cervical/ Vulvar/Vaginal cancer,

- H/O Immunosuppression after solid organ transplantation.

Endorectal ultrasound (ERUS) of anal cancer is a valuable and sensitive tool for assessing the extent of tumor infiltration and perianal lymph node involvement ERUS of anal canal allows an exact local staging of a primary anal canal carcinoma and the followup in irradiated carcinomas. ${ }^{1}$

Until two decades ago, abdominoperineal resection with colostomy was the preferred surgical procedure for most 
major cancers of the anal canal and at present it remains the salvage surgical procedure of choice for local recurrence or if there is biopsy proven tumor after initial chemoradiation therapy or for patients who are unlikely to tolerate chemoradiation or have pre-existing impaired continence. Local excision with wide margins considered in well-tomoderately differentiated tumors, which are less than $2 \mathrm{~cm}$ in size and invade only upto the submucosal or for those who are medically unfit for major surgery.

The most important prognostic factors are the size of the tumor, depth of invasion and extent of spread at the time of diagnosis with the higher T-stage correlating with worse prognosis. Lymphadenopathy also carries a worse prognosis with probability of cure reduced to approximately $50 \%$ in cases with nodal involvement.

Miles' observed lymph node metastases along the mesorectum and the vessels as far as the inferior mesenteric artery and aorta in patients with rectal cancer. He was convinced that removal of the upward spread of rectal cancer affected the cure rate after resection as much as removal of the tumor itself.

Miles' believed that the levators, ischiorectal fat and even the perineal skin were "Highly Dangerous Tissues." He reported no less than 31 recurrences in the ischiorectal fat, which he believed as inferior haemorrhoidal nodes left behind by the surgeon. Miles' concept of a cylindrical field of spread remained indelibly printed on the minds of surgeons and oncologists. ${ }^{2}$

During the past two decades, low anterior resection (LAR) with colorectal or coloanal anastomosis has replaced APR as the primary surgical therapy for rectal cancer. Several studies have shown that outcome after LAR with deep anastomosis and APR is comparable concerning mortality, local recurrence rate and survival. Adequate clearance of the tumor and not the surgical procedure performed is the determinant factor influencing outcome.

Most tumors in the upper third and midrectum are amenable to a sphincter saving procedure (SSP). The lower thirds of rectum is of debate in this aspect.

Low-grade tumors with $\mathrm{T}_{2} / \mathrm{T}_{3}$ stage located above $3 \mathrm{~cm}$ from dentate line or $5 \mathrm{~cm}$ from anal verge are amenable to low anterior resection.

Wolmark and Fisher. ${ }^{3}$ in a multi-institutional study of 232 patients undergoing APR and 181 undergoing SSP have identified specific risk factors for local recurrence-advanced Dukes' staging and poorly differentiated histological grades. At a mean followup period of 48 months, APR had no survival advantage over LAR despite comparing cohorts according to Dukes' stage, number of +ve lymph nodes and tumor size. ${ }^{3}$

Isenberg and Keller. ${ }^{4}$ (1995) in a retrospective study compared local and distant recurrence with survival after SSP and APR. In their study of 71 women and 71 men with a primary adenocarcinoma between 5-10 from anal verge, 89 SSR and 53 APR were performed.

Survival was not different between the procedures in Dukes' stage A and B. A survival advantage for patients with Dukes' C carcinoma, after APR, did not reach statistical significance.

No differences in distant spread were found and also for local recurrence in Dukes' stage A and B after SSP and APR.
However, there was significant increase in local recurrence rate in Dukes' stage C after SSP (24\%) v/s APR (5\%).

Although, a further resection could be performed in almost all of these patients, a negative effect of local recurrence on survival occurred (25.4 months with and 80 months without local recurrence).

This study concluded that APR is indicated in rectal carcinoma of middle and lower $1 / 3^{\text {rd }}$ and can be avoided only if total removal of mesorectum can be performed, which is essential in Dukes' C carcinoma. ${ }^{4}$

Adenocarcinoma of rectum may spread to adjacent tissues by either of the two routes.

1. Proximally to lymph nodes along superior haemorrhoidal vessels and inferior mesenteric vessels.

2. Laterally into mesorectum and perirectal soft tissue, hence the essential features of the operation are an adequate proximal lymphadenectomy and the widest possible lateral margins in the pelvis.

The principal goal of resection of a rectal carcinoma is to avoid a loco-regional recurrence. Hence, it is important for a curative resection to avoid intra-operative dissemination of tumour cells by manipulation or perforation of the tumor.

Spontaneous/iatrogenic perforation of tumor has a -ve impact on both the rate of locoregional recurrence and the survival. Significantly, greater tumor cell dissemination was observed after APR compared with AR. ${ }^{5}$

Slanetz, Harter, Grinnell. ${ }^{6}$ (1972) analyzed AR v/s APR or cancer of the rectum and rectosigmoid in 524 cases; 277 APR and 247 AR performed between years 1944-1963 for single primary malignant lesion located between 8-18 cm from anal verge were compared.

They concluded that for tumors of the rectum and rectosigmoid above level of $8 \mathrm{~cm}, \mathrm{AR}$ is the equal of APR as a cancer operation with significantly lower morbidity and mortality rates than with APR. They found overall 5 years survival after APR of $47 \%$ and after AR of $56 \%$. On comparing the distribution of cases by Dukes' classification, they found a preponderance of Dukes' $\mathrm{C}$ tumors in patients undergoing APR and a relatively higher proportion of Dukes' A and B lesions in those undergoing AR. However, $5 \%$ superiority was found for AR as compared to APR in each of the three Dukes' categories. ${ }^{6}$

Further, they concluded that between 8 and $18 \mathrm{~cm}$, the level of the tumor cannot be related to survival or recurrence rates and should not influence the surgeon's choice of procedure as long as an adequate distal margin of resection can be provided.

About patterns of local recurrence, they found that roughly $1 / 3^{\text {rd }}$ of Dukes' $C$ tumors recurred in the pelvic area within the first 5 post-operative years; $10 \%$ of Dukes' B lesions re-emerged locally and even in Dukes' A about 5\% reappeared locally.

Rates of local recurrence were lesser after AR, but they found that locally extensive lesions were managed most often by APR and APR was employed more frequently when intraoperative bowel or tumor perforation occurred. Both these phenomena predisposed to development of local recurrence. 6 
There were 24 instances of local recurrence among 73 survivors of AR for Dukes' C tumors; 15 out of these 24 required colostomies for obstruction. Roughly, 115 of all patients undergoing curative anterior resection (AR) for Dukes' B and C lesions will ultimately have intestinal obstruction in the pelvis requiring proximal decompression of palliative nature.

Williams and Johnston (1984). ${ }^{7}$ compared survival and recurrence in patients with carcinoma of middle third of rectum (7.5-12 cm from anal verge), who were treated by APR (83 patients) and low SSR (71 patients). APR patients were found to have tumors with less favourable pathological features. To minimize bias between the two groups, patients with tumors with similar pathological characteristics were compared. The overall cancer specific 5 -year survival rate after SSR was $74 \%$ and after APR was $62 \%$. The overall recurrence rates were $27 \%$ after SSR and $41 \%$ after APR; incidence of local recurrence was $11 \%$ after SSR and $8 \%$ after APR.

Their results suggested that patients with carcinoma of the middle third of rectum, who are treated by SSR fare as well as patients who are treated by APR with respect to both recurrence and survival. Henrichsen and Christiansen. ${ }^{8}$ (1989) studied the prognostic staging of extraperitoneal rectal cancer in 375 patients who had curative resection for cancer of the rectum below the peritoneal reflection.

Prognosis was evaluated according to four currently used staging systems, i.e., Dukes' system, the modified TNM system described by the American Joint Committee for cancer staging, the Australian Clinicopathological staging system and the Astler Coller staging system. They indicated that the simpler Dukes' system gives as good a prognostic differentiation as any other system in current use. It was further demonstrated that an important prognostic separation can be obtained by dividing the "B" group of Dukes' staging system into tumors that reach the surface of the muscularis propria and those with demonstrable invasion of extrarectal structures, the latter having as bad a prognosis as Dukes' C tumors.

Dawson, Blair, Begent et al. ${ }^{9}$ (1991) studied RIGS (Radioimmunoguided surgery) using an anti-CEA (A5B7) monoclonal antibody in 52 patients undergoing surgery for colorectal cancer. The antibody localized $97.8 \%$ of primary tumors and $88.8 \%$ of the principal tumors in second look procedures.

RIGS in primary colorectal carcinoma can provide additional information concerning extent of locally advanced tumors in particular and the principal that the subsequent surgery may be influenced has been established. RIGS correctly predicted the subsequent Dukes' staging in $77 \%$ of first look laparotomies, although accurate identification of individual nodes was impossible. Out of 43 primary excisions, the technique influenced the surgical procedure performed in 2 cases $(4.6 \%)$ and in three of 9 patients undergoing second look laparotomy (33\%). The technique appears to have a greater role in second look procedures where it may help determine the extent of recurrent tumor. They concluded that larger followup series are required to define how the additional information provided by this technique may best be exploited.
Rouanet, Senesse et al.10 (1999) conducted a study to investigate the oncological, functional and quality of life results of dynamic graciloplasty and reconstruction of anal sphincter after an APR for carcinoma.

Fleshman and Wexner et al.11 (1999) compared the safety and efficacy of laparoscopic v/s open APR for cancer. Records of 194 patients who underwent laparoscopic APR (42) or open APR (192 patients) at three institutions between years 1991-97 were reviewed.

Tumor recurrence was similar for both local (19\% and $14 \%$ ) and distant (38\% and $26 \%$ ) recurrence. Survival rates were also similar.

A retrospective review of 89 patients treated by APR at a single centre between years 1992-2000 was done, comparing the cancer specific outcomes of the laparoscopic cohort with the open cohort; 28 operations were done laparoscopically and 61 were open. The two groups were matched for age and stage of the disease. No difference in the mean length of overall survival in overall recurrence rate, isolated recurrence rate or distant recurrence rates were seen nor was there any difference in the disease-free period.

The laparoscopic cohort did have a significantly shorter length of stay compared with open cohort (13 days v/s 18 days). Therefore, they concluded that laparoscopic APR of the rectum for cancer does not compromise cancer specific survival outcomes and has benefits like avoidance of a large abdominal wound which improves cosmesis and contributes to significantly shorter length of stay.

AIMS AND OBJECTIVES: To study the recurrence rates, that is local recurrence as well as distant metastasis in the follow up of the patients undergoing abdominoperineal resection for carcinoma anorectum.

\section{MATERIAL AND METHODS:}

Period of Study: 75 patients operated for APR in last 10 years were studied retrospectively and 25 patients operated for the same in two years were studied prospectively and were followed upto two years.

\section{Inclusion Criteria:}

a) Histologically proven cases of carcinoma anorectum.

b) Patients who underwent surgery at our centre and were subsequently treated at our centre.

Exclusion Criteria: Patients not surgically treated at our centre but outside.

METHODOLOGY: Information regarding the patients was collected from their record files and was arranged to determine the profile as follows:

a) Age and Sex Distribution,

b) Clinical Presentation: Chief Complaints,

c) Examination: Digital Rectal Examination,

d) Investigations: Mainly staging investigations.

Preoperative confirmation of the tumor by biopsy was obtained in all patients:

a) Operative Findings: Nature of growth,

b) Histopathology and Staging, 
c) Disease Recurrence: Distant metastasis and local recurrence.

CLINICAL PRESENTATION: Clinical presentation in terms of chief complaints like bleeding per rectum, altered bowel habits and loss of weight etc., were recorded.

Findings on per rectal examination like distance of growth from anal verge were recorded.

INVESTIGATIONS: Besides routine investigations, staging workup included:

- Chest X-ray,

- Ultrasonography Abdomen,

- CT Scan Abdomen and Pelvis,

\section{Other investigations done were,}

i. Colonoscopy to exclude synchronous lesions. (There is a $3.5 \%$ incidence of synchronous carcinomas in patients with single lesion of colorectal cancer).

ii. Tumor Marker Study: Carcinoembryonic antigen (CEA).

Preoperative Preparation: Of the patient was done in all cases with combination of mechanical bowel preparation (Polyethylene glycol solution) and antibiotics (Combination of third generation cephalosporin and metronidazole).

A formal consent for permanent colostomy was obtained in all cases after a complete discussion with the patient's family members.

Operative Approach: Abdominoperineal Resection (APR) was carried out in the modified lithotomy Trendelenburg position under a combination of general anaesthesia, epidural or both.

A Foley's self-retaining catheter and a nasogastric tube were placed in the bladder and the stomach respectively before surgery.

The abdominal part of the resection was done through a vertical midline lower abdominal incision and the perineal part was done through a rhomboid incision made around the anal orifice after placing a purse-string suture around the anus following the synchronous combined approach.

Mobilization of the rectum was achieved through the abdominal incision after dividing its attachments all around.

The ureters were identified and saved from injury. The inferior mesenteric artery was traced and its branches to the sigmoid colon and rectum were doubly ligated and divided.

The posterior vaginal wall was resected in females in cases with rectal tumors on the anterior wall. Colon was divided at the descending colon and sigmoid junction and with the constant guidance by the perineal surgeon was delivered through the perineum.

The perineal wound was closed in layers and two closed suction drains were placed in the pelvis and brought out through the perineum. End colostomy was fashioned and the space lateral to the colon in the paracolic gutter was obliterated with sutures.

Closure of the pelvic floor was done with sutures or omentum was mobilized down to the pelvic floor. Abdomen was closed in layers and colostomy was matured.

Post-Operative Period: Post-operative morbidity and mortality were recorded with reference to intra-operative, immediate and delayed complications.

Disease recurrence was recorded with special reference to:

a. Distant metastases,

1. Liver, Lungs, Brain, Bones.

2. Inguinal lymph nodes.

b. Local recurrence,

1. Pelvis, Posterior Vaginal wall.

2. Perineum.

3. Locoregional lymph nodes.

RESULTS: Analysis of 75 patients of carcinoma anorectum undergoing abdominoperineal resection for a period of 10 years was done retrospectively and 25 patients were similarly analysed prospectively for 2 years. Their management was based on clinical findings and histopathological report.

Results after surgery are presented in terms of disease recurrence - local/distant metastases and overall survival.

\section{RETROSPECTIVE GROUP:}

Disease Recurrence: Disease recurrence was anlayzed in our retrospective group of 75 paitents in two categoires:

a) Distant Metastasis,

b) Local Recurrence.

\begin{tabular}{|c|c|c|c|c|c|c|c|}
\hline Sl. No. & Staging after APR & Liver & Lungs & Brain & Kidneys & Death & Last FU \\
\hline 1 & $\begin{array}{c}\mathrm{T}_{3} \mathrm{~N}_{0} \mathrm{M}_{0} \\
(\text { Dukes' B) }\end{array}$ & 1 & & & & $\begin{array}{l}1 \text { (cardiac arrest } \\
\text { during CCT) }\end{array}$ & \\
\hline 2 & $\begin{array}{c}\text { Malignant melanoma anorectum } \\
\text { (Also had cervical lymph node mets.) (Dukes' } \\
\text { B) }\end{array}$ & 1 & & 1 & 1 & Lost to follow up & \\
\hline 3 & $\mathrm{~T}_{3} \mathrm{~N}_{0} \mathrm{M}_{0}\left(\right.$ Dukes' $\left.^{\prime} \mathrm{C}\right)$ & 1 & 1 & 1 & & Death & \\
\hline 4 & $\mathrm{~T}_{4} \mathrm{~N}_{0} \mathrm{M}_{0}$ (Also vaginal vault) & 1 & 1 & & & Death & \\
\hline 5 & $\mathrm{~T}_{3} \mathrm{~N}_{1} \mathrm{M}_{0}$ & & 1 & & & & $\begin{array}{c}10 \\
\text { months }\end{array}$ \\
\hline 6 & $\begin{array}{l}\text { Malignant melanoma (With inguinal lymph } \\
\text { node mets) }\end{array}$ & 1 & & & & & 2 months \\
\hline 7 & $\begin{array}{c}\mathrm{T}_{3} \mathrm{~N}_{0} \mathrm{M}_{0} \text { (Also metastasis to para-aortic region } \\
\text { and R. Inguinal LNS) (Dukes' B) }\end{array}$ & 6 & 3 & 2 & 1 & 3 deaths & \\
\hline
\end{tabular}


In our patients, metastases after APR for carcinoma anorectum was recognized in four different organs mainly liver, lungs, brain and kidneys.

Hence, 7 (9.1\%) of our 75 patients showed evidence of distant metastases, of which 3 have died and the rest have been lost to follow up and have presumably died. Liver metastasis were seen in 6 patients (8\%), Lungs $3(4 \%)$, Brain $2(2.6 \%)$ patients. Dukes' B was the stage in 4 of these patients and Dukes' $\mathrm{C}$ in 1 patient; 2 patients (2.6\%) had malignant melanoma.

DISSEMINATED DISEASE: One of our patients, a 40 years old female with histopathological staging of $\mathrm{T}_{3} \mathrm{~N}_{0} \mathrm{M}_{0}$ (Dukes' $\mathrm{B}$ ) after APR was re-explored 4 months later for adhesive intestinal obstruction.

She was found to have disseminated disease on reexploration with multiple satellite nodules involving almost the entire gut and peritoneal surface. She followed up for about 7 months afterwards without receiving any treatment and was thereafter lost to follow up and has presumably died.

\section{LOCAL DISEASE RECURRENCE:}

Prostate: After APR, two (2.66\%), out of the total male patients analyzed, developed recurrent disease involving the prostate.
A 54 year old male presented about 1 year and 6 months after APR with difficulty in maturation for which Channel's operation was done and the histopathology of prostate was consistent with metastatic adenocarcinoma.

Patient developed urinary fistula between scrotum and anus subsequently and CT scan pelvis revealed fistulous posterior urinary bladder wall possibly due to disease recurrence. Urinary diversion with ileal conduit was done for the patients 2 months after the Channel's operation and patient did well in followup for about 3 months after which he was lost to follow up.

Another 65 years old male underwent Channel's operation about 2 months after APR for complaints of retention of urine. His histopathology of prostate was consistent with poorly differentiated carcinoma. His histopathology of APR was poorly differentiated adenocarcinoma, rectum $\left(\mathrm{T}_{3} \mathrm{~N}_{0} \mathrm{M}_{0}\right)$. Patient was lost to follow up.

Local recurrence in the pelvic region or presacral area with or without involvement of regional lymph nodes of the pelvis and lower abdomen was seen in 15 (20\%) of our retrospective group of 75 patients analyzed.

In six of these fourteen, local recurrence in the pelvis was peculiarly found to be associated with obstructive uropathy and bilateral hydronephrosis and hydroureter of varying degree of severity along with features of deterioration of renal function.

\begin{tabular}{|c|c|c|c|c|c|}
\hline Sl. No. & $\begin{array}{c}\text { Histopathology } \\
\text { stage after APR }\end{array}$ & Region Involved & $\begin{array}{c}\text { Detection of Local } \\
\text { Recurrence after APR (Duration) }\end{array}$ & Death & Lost to follow-up \\
\hline 1 & $\mathrm{~T}_{3} \mathrm{~N}_{0} \mathrm{M}_{0}$ (Dukes' B) & Presacral region & 3 months & - & 1 year 6 months \\
\hline 2 & $\mathrm{~T}_{2} \mathrm{~N}_{0} \mathrm{M}_{0}$ (Dukes' B) & Pelvis and perineum & 6 months & - & Lost to F.U. \\
\hline 3 & $\mathrm{~T}_{3} \mathrm{~N}_{2} \mathrm{M}_{0}$ (Dukes' B) & Pelvis & 6 months & - & 1 year 6 months \\
\hline 4 & $\mathrm{~T}_{3} \mathrm{~N}_{0} \mathrm{M}_{0}$ (Dukes' B) & Site of rectal resection & 1 year & - & Lost to F.U. \\
\hline 5 & $\mathrm{~T}_{3} \mathrm{~N}_{0} \mathrm{M}_{0}$ (Dukes' B) & R adrenal area (CT) and pelvis & 5 months & - & 2 months \\
\hline 6 & $\mathrm{~T}_{3} \mathrm{~N}_{0} \mathrm{M}_{0}$ (Dukes' C) & B/L Inguinal LN' and Pelvis & 2 months & - & Lost to F.U. \\
\hline \multicolumn{7}{|c|}{ Table 2: Local Recurrence Associated with Obstructive Uropathy } \\
\hline
\end{tabular}

\begin{tabular}{|c|c|c|c|c|c|}
\hline Sl. No. & $\begin{array}{l}\text { Histopathology } \\
\text { stage after APR }\end{array}$ & Region Involved & $\begin{array}{c}\text { Associated Disease } \\
\text { Reoccurrence in other } \\
\text { area }\end{array}$ & $\begin{array}{c}\text { Detection of } \\
\text { Recurrence after } \\
\text { APR } \\
\end{array}$ & $\begin{array}{c}\text { Death/Last } \\
\text { FU }\end{array}$ \\
\hline 1 & $\mathrm{~T}_{3} \mathrm{~N}_{0} \mathrm{M}_{0}$ & Presacral & - & 9 months & 1 months \\
\hline 2 & $\mathrm{~T}_{2} \mathrm{~N}_{0} \mathrm{M}_{0}$ & Posterior to U bladder & Para-aortic hypogastric & 5 years & 3 months \\
\hline 3 & $\mathrm{~T}_{3} \mathrm{~N}_{2} \mathrm{M}_{0}$ & $\begin{array}{c}\text { Pelvis, post vaginal } \\
\text { wall }\end{array}$ & Internal and ext. iliac $\mathrm{LN}^{\mathrm{S}}$ & 7 months & 3 months \\
\hline 4 & $\mathrm{~T}_{4} \mathrm{~N}_{3} \mathrm{M}_{0}$ & $\begin{array}{l}\text { Posterior to urinary } \\
\text { bladder }\end{array}$ & L. Iliac Group LNS & 6 months & Lost to F.U. \\
\hline 5 & $\mathrm{~T}_{3} \mathrm{~N}_{0} \mathrm{M}_{0}$ & Pelvis, presacral area & Iliac and Hypogastric LNS & 11 months & 5 months \\
\hline 6 & $\mathrm{~T}_{2} \mathrm{~N}_{0} \mathrm{M}_{0}$ & Perineum & - & 2 years & Death \\
\hline 7 & $\mathrm{~T}_{2} \mathrm{~N}_{0} \mathrm{M}_{0}$ & Pelvis & Para-aortic nodes & 1 year & Lost to F.U. \\
\hline 8 & $\mathrm{~T}_{4} \mathrm{~N}_{0} \mathrm{M}_{0}$ & Pelvis & & 1 year & Lost to F.U. \\
\hline 9 & $\mathrm{~T}_{3} \mathrm{~N}_{0} \mathrm{M}_{0}$ & Para-aortic & R. Inguinal Liver Mets & 5 months & Lost to F .U. \\
\hline
\end{tabular}




\begin{tabular}{|c|c|c|c|c|}
\hline Sl. No. & Stage & Involvement & Duration & Death/Last FU \\
\hline 1 & $\mathrm{~T}_{3} \mathrm{~N}_{0} \mathrm{M}_{0}$ (Adenocarcinoma) & Bilateral & 2 months & Lost to F.U. \\
\hline 2 & $\begin{array}{c}\mathrm{T}_{2} \mathrm{~N}_{0} \mathrm{M}_{0} \text { (Also had liver mets and Para- } \\
\text { aortic LN involvement) } \\
\text { (Dukes' B) }\end{array}$ & Right sided & 9 years & Lost to F.U. \\
\hline 3 & $\begin{array}{c}\mathrm{T}_{3} \mathrm{~N}_{0} \mathrm{M}_{0} \text { (Also had liver mets and Para- } \\
\text { aortic LN Involvement) (Duke's B) }\end{array}$ & Right sided & 5 months & Lost to F.U. \\
\hline 4 & $\begin{array}{c}\text { Malignant Melanoma (R side IBD } \\
\text { performed also develop liver mets) }\end{array}$ & Left sided & 2 months \\
\hline \multicolumn{2}{|r}{ Table 4: Inguinal Lymph Node Metastases } \\
\hline
\end{tabular}

Four $(5.2 \%)$ of our patients developed metastases to the inguinal lymph nodes. Three had unilateral and one had bilateral inguinal lymph node metastases.

\begin{tabular}{|c|c|c|c|c|}
\hline Sl. No. & Histopath. stage after APR & Site & $\begin{array}{l}\text { Recurrence detected } \\
\text { after APR }\end{array}$ & Follow Up \\
\hline 1 & $\mathrm{~T}_{3} \mathrm{~N}_{1} \mathrm{M}_{0}$ (Dukes' C) & Posterior vaginal wall & 9 months & Lost to F.U. \\
\hline 2 & $\mathrm{~T}_{3} \mathrm{~N}_{1} \mathrm{M}_{0}($ Dukes' C) & $\begin{array}{l}\text { Posterior vaginal wall associated with } \\
\text { Grade III (hydronephrosis) }\end{array}$ & 3 years 5 months & Lost to F.U. \\
\hline 3 & $\mathrm{~T}_{2} \mathrm{~N}_{0} \mathrm{M}_{0}$ (Dukes' B) & Posterior vaginal wall & 1 year 3 months & $\begin{array}{l}\text { Lost to F.U. } \\
\text { after } 7 \\
\text { months }\end{array}$ \\
\hline 4 & $\mathrm{~T}_{3} \mathrm{~N}_{0} \mathrm{M}_{0}$ (Dukes' B) & $\begin{array}{l}\text { Posterior vaginal wall (Assoc.) with } \\
\text { local disease in Pelvis and regional } \\
\text { lymph node) }\end{array}$ & 11 months & $\begin{array}{l}\text { Lost to F.U. } \\
\text { after } 3 \\
\text { months }\end{array}$ \\
\hline 5 & $\begin{array}{c}\mathrm{T}_{4} \mathrm{~N}_{2} \mathrm{M}_{0} \text { (Had post vaginal } \\
\text { wall infiltration } \\
\text { preoperatively) } \\
\text { (Dukes' C) }\end{array}$ & $\begin{array}{l}\text { Vaginal vault recurrence + Lung and } \\
\text { Liver mets. }\end{array}$ & 8 months & Lost to F.U. \\
\hline \multicolumn{5}{|c|}{ Table 5: Local Recurrence involving Posterior Vaginal Wall/Vaginal Vault } \\
\hline
\end{tabular}

After APR, five (6.5\%) of our patients developed local disease recurrence involving either posterior vaginal wall or vaginal vault.

PROSPECTIVE GROUP: In the prospective group of 25 patients, median age was 55 years. Age range was $30-90$ years. There were 16 males (64\%) and 9 females (36\%). Male-to-female ratio was 1.77:1.

\begin{tabular}{|c|c|c|c|}
\hline Age & Males & Females & Total \\
\hline 20-40 years & 1 & 4 & 5 \\
\hline 40-50 years & 3 & 3 & 6 \\
\hline 50-60 years & 7 & - & 7 \\
\hline 60-70 & 2 & 1 & 3 \\
\hline$>70$ years & 3 & 1 & 4 \\
\hline \multicolumn{4}{|c|}{ Table 6: Prospective Group } \\
\hline
\end{tabular}

The average age was 54.92 years with standard deviation of 14.16 years. The median age was 55 years with mode of 40 years.
DISEASE RECURRENCE: Disease recurrence in the prospective group was also studied under two categories

- Distant metastasis

- Local disease recurrence

\begin{tabular}{|c|c|c|c|c|}
\hline $\begin{array}{c}\text { Sl. } \\
\text { No. }\end{array}$ & $\begin{array}{c}\text { Histopathology } \\
\text { stage after APR }\end{array}$ & Liver & Bone & $\begin{array}{c}\text { Death/Last } \\
\text { FU }\end{array}$ \\
\hline 1 & $\mathrm{~T}_{3} \mathrm{~N}_{0} \mathrm{M}_{0}$ & 1 & & 2 months \\
\hline 2 & $\begin{array}{c}\text { Anaplastic } \\
\text { malignancy }\end{array}$ & 1 & 1 & Lost to FU \\
\hline 3 & $\mathrm{~T}_{3} \mathrm{~N}_{1} \mathrm{M}_{0}$ & 1 month \\
\hline 4 & $\begin{array}{c}\mathrm{T}_{3} \mathrm{~N}_{2} \mathrm{M}_{0} \\
\text { (Also developed } \\
\text { paraaortic } \\
\text { LNS and right } \\
\text { common iliac } \\
\text { lymph nodes) }\end{array}$ & - & $\begin{array}{c}1 \\
\text { Thoracic } \\
\text { and } \\
\text { lumbar } \\
\text { vertebrae) }\end{array}$ & 1 month \\
\hline
\end{tabular}

Table 7: Distant metastasis

\begin{tabular}{|c|c|c|c|}
\hline $\begin{array}{c}\text { Histopathology } \\
\text { stage after APR }\end{array}$ & Region Involved & $\begin{array}{c}\text { Detection of Local Recurrence } \\
\text { after APR (Duration) }\end{array}$ & Death/Last FU \\
\hline $\mathrm{T}_{3} \mathrm{~N}_{2} \mathrm{M}_{0}$ (Dukes' C) & $\begin{array}{c}\text { B/L inguinal obturator, common iliac lymph } \\
\text { nodes + severe Hydronephrosis (treated by PCN) }\end{array}$ & 7 months & $\begin{array}{c}3 \mathrm{months} \\
\text { (lost to FU) }\end{array}$ \\
\hline $\begin{array}{c}\text { Anaplastic } \\
\text { malignancy }\end{array}$ & $\begin{array}{c}\text { Recurrent lesion adherent to posterior urinary } \\
\text { bladder wall }\end{array}$ & 1 month & Lost to FU \\
\hline $\mathrm{T}_{3} \mathrm{~N}_{2} \mathrm{M}_{0}$ & Perineal region & $<1$ month & 1 month \\
\hline $\mathrm{T}_{2} \mathrm{~N}_{0} \mathrm{M}_{0}$ & Perineal region + Vaginal involvement & 7 months & Death \\
\hline Basaloid carcinoma & Vulva (Vulvectomy performed) & 2 months & 1 year 3 months \\
\hline $\mathrm{T}_{3} \mathrm{~N}_{2} \mathrm{M}_{0}$ & $\begin{array}{c}\text { Paraaortic and R. common iliac lymph nodes } \\
\text { (Also developed bone mets) }\end{array}$ & - & 1 month \\
\hline
\end{tabular}

\section{Table 8: Local Recurrence}




\begin{tabular}{|c|c|c|c|}
\hline $\begin{array}{c}\text { Histopathology } \\
\text { stage after APR }\end{array}$ & Region Involved & $\begin{array}{c}\text { Detection of Local } \\
\text { Recurrence after APR } \\
\text { (duration) }\end{array}$ & Death/Last FU \\
\hline $\mathrm{T}_{3} \mathrm{~N}_{0} \mathrm{M}_{0}$ (Dukes' $\mathrm{B}$ ) & $\begin{array}{c}\text { (Left sided) (Left IBD done) HPR +ve for } \\
\text { metastatic adenocarcinomatous deposits }\end{array}$ & 3 months & 2 years (Alive) \\
\hline $\mathrm{T}_{3} \mathrm{~N}_{2} \mathrm{M}_{0}$ (Dukes' C) & Bilateral & 7 months & 3 months (lost to FU) \\
\hline \multicolumn{2}{|c|}{ Table 9: Inguinal Lymph Node Metastases } \\
\hline
\end{tabular}

\section{OBSERVATIONS - RETROSPECTIVE GROUP DISEASE RECURRENCE:}

Distant Metastases: In our analysis, in the retrospective group 7 patients $(9.1 \%)$ showed evidence of distant metastases. Liver metastases were seen in 6 patients (8.4\%). Lung and brain metastases were seen in 3 patients (3.9\%) and 2 patients $(2.6 \%)$ respectively. Dukes' B was the stage in 4 of these 7 patients and Dukes' $\mathrm{C}$ in 1 patient; 2 patients were of malignant melanoma. One patient of stage Dukes' B developed disseminated disease in the abdomen.

Inguinal Lymph Node Metastases: In retrospective study, 4 patients (5.2\%) developed inguinal lymph node metastases.

Local Recurrence: In our study, in retrospective group 17 patients $(22.66 \%)$ developed local recurrence and 6 patients (7.8\%) developed obstructive uropathy along with it.

Local recurrence was seen in the pelvis, presacral area, perineum and loco regional lymph nodes. Dukes' B was the stage in 14 patients (82.35\%) and Dukes' C was stage in 3 $(17.7 \%)$ of these patients.

Posterior Vaginal Wall/Vault Recurrence: In retrospective group, 5 patients $(6.5 \%)$ had posterior vaginal wall/vault recurrence. Dukes' $\mathrm{C}$ was the stage in 3 of these followed by Dukes' B in 2 patients.

\section{OBSERVATIONS - PROSPECTIVE GROUP DISEASE RECURRENCE}

Distant Metastases: In the prospective group, 4 patients (16\%) showed evidence of distant metastases. Liver metastases were seen in 3 patients (12\%). Bone metastases was seen in 1 patient (4\%) Dukes' B was the stage in 1 of these 4 patients and Dukes' $C$ in 2 patients.

Inguinal Lymph Node Metastases: In prospective study, 2 patients (8\%) developed inguinal lymph node metastases.

Local Recurrence: In prospective group, 6 patients (24\%) developed local recurrence and 1 patient (4\%) developed obstructive uropathy along with it. Dukes' $\mathrm{C}$ was the stage in 3 patients (50\%) and Dukes' B was stage in $1(16.6 \%)$ of these patients.

Posterior Vaginal Wall/Vault Recurrence: There were no recurrences in prospective group.
OBSERVATIONS: (Both for Prospective Group and Retrospective Group)

\begin{tabular}{|c|c|}
\hline Disease Recurrence & \\
\hline a) Distinct metastasis were seen in & $\begin{array}{l}11 \text { patients } \\
(11 \%)\end{array}$ \\
\hline i) Liver metastases were seen in & 9 patients $(9 \%)$ \\
\hline ii) Lung metastases were seen in & 3 patients (3\%) \\
\hline $\begin{array}{l}\text { b) Inguinal lymph node metastasis } \\
\text { were seen in }\end{array}$ & 6 patients $(6 \%)$ \\
\hline $\begin{array}{l}\text { c) Local disease recurrence } \\
\text { developed in }\end{array}$ & $\begin{array}{c}23 \text { patients } \\
(23 \%)\end{array}$ \\
\hline $\begin{array}{l}\text { d) Posterior vaginal wall/vault } \\
\text { recurrence seen in }\end{array}$ & 5 patients $(5 \%)$ \\
\hline
\end{tabular}

DISCUSSION: Colorectal cancer is the fourth most common variety of malignant tumor found in women and its frequency in men is surpassed only by carcinoma of bronchus. The rectum remains the most frequent site involved. Carcinoma of the rectum can occur early in life, but the adult age of presentation is usually above 65 years.

\section{DISEASE RECURRENCE:}

Distant Metastases: In our analysis, in the retrospective group 7 patients $(9.1 \%)$ showed evidence of distant metastases. Liver metastases were seen in 6 patients $(8.4 \%)$. Lung and brain metastases were seen in 3 patients $(3.9 \%)$ and 2 patients $(2.6 \%)$ respectively.

Dukes' B was the stage in 4 of these 7 patients and Dukes' $\mathrm{C}$ in 1 patient; 2 patients were of malignant melanoma. One patient of stage Dukes' B developed disseminated disease in the abdomen.

In the prospective group 4 patients (16\%) showed evidence of distant metastases. Liver metastases were seen in 3 patients $(12 \%)$. Bone metastases was seen in 1 patient (4\%). Dukes' B was the stage in 1 of these 4 patients and Dukes' $\mathrm{C}$ in 2 patients. Zaheer et al.12 have also found liver as the most commonly involved organ in stage D' disease.

Luna, Perez et al. ${ }^{13}$ found an incidence of distant metastasis of $35 / 137$ (25.7\%) in their patients, Rosen, Veidenheimer et al. ${ }^{14}$ quoted an incidence of distant metastasis of (33\%) in their 230 patients who had undergone operation for APR.

Nissan Guillem et al. ${ }^{15}$ quoted an incidence of distant metastasis of $22 \%(64 / 292)$ patients. Zaheer et al. ${ }^{12}$ found an incidence of distant metastasis of $11.2 \%$ (19/169) patients Fick et al. ${ }^{16}$ found an incidence of $30 \%$ out of 68 APR done.

Inguinal Lymph Node Metastases: In retrospective study, 4 patients $(5.2 \%)$ developed inguinal lymph node metastases. In prospective study, 2 patients $(8 \%)$ developed inguinal lymph node metastases. Nissen Guillam et al.15 had found Inguinal lymph node metastasis in 4/64 (6\%). 
Local Recurrence: In our study, in retrospective group 17 patients $(22.66 \%)$ developed local recurrence and 6 patients (7.8\%) developed obstructive uropathy along with it.

Local recurrence was seen in the pelvis, presacral area, perineum and locoregional lymph nodes. Dukes' B was the stage in 14 patients $(82.35 \%)$ and Dukes' C was stage in 3 $(17.7 \%)$ of these patients.

In prospective group 6 patients (24\%) developed local recurrence and 1 patient (4\%) developed obstructive uropathy along with it.

Dukes' $\mathrm{C}$ was the stage in 3 patients (50\%) and Dukes' B was stage in $1(16.6 \%)$ of these patients.

Local recurrence reported as in literature by Slanetz, Herter et al. ${ }^{6}$ was Dukes' B in 25\% and Dukes' C in 38\%.

Dixon and Maxwell et al. ${ }^{17}$ have quoted a rate of $14 \%$ of pelvic recurrence for 12 patients/85 and 9 of these were Dukes' C. Isenberg and Keller. ${ }^{4}$ in their 53 patients have reported local recurrence rate of $5.7 \%$ and distant metastasis rate of $9.4 \%$.

McFarlane et al. (1993) have quoted local recurrence rate of $22 \%$ after APR. Braun et al. (1992) have quoted local recurrence rate of $21 \%$ after APR. Gillen and Peel (1986) have quoted local recurrence rate of $25 \%$ after APR. Local recurrence is an indicator of surgical technique failure in cancer treatment and produces the worst form of death for the patients, producing pain, incontinence and discharge etc.

Posterior Vaginal Wall/Vault Recurrence: In retrospective group, 5 patients $(6.5 \%)$ had posterior vaginal wall/vault recurrence. Dukes' $\mathrm{C}$ was the stage in 3 of these patients, followed by Dukes' $B$ in 2 patients. There were no recurrences in prospective group.

\section{CONCLUSIONS:}

1. Colorectal cancer is the most common malignancy of the gastrointestinal tract. Rectum remains the most common site affected by it. Carcinoma anal canal is about one tenth as common as rectal cancer.

2. Abdomino-perineal resection remains the 'gold standard' for low lying $(<5 \mathrm{~cm}$ from anal verge $)$ advanced carcinoma anorectum.

3. Local disease recurrence is quite common following APR and distant metastases are also seen, most commonly to the liver and lungs.

\section{BIBLIOGRAPHY:}

1. Beynon J, Mortensen N, Foy DM et al. The Detection and Evaluation of Locally recurrent Rectal Cancer with Rectal Endosonography. Dis Colon Rectum. 1989; 32: 509-51.

2. Heald RJ, Smedh RK, Kald A, Sexton R, Moran BJ. Abdominoperineal excision of the rectum-An endangered operation. Dis colon Rectum. 1997; 40(7): 47-51.

3. Wolmark N, Fisher B. An analysis of survival and treatment failure following abdominoperineal and sphincter saving resection in Dukes' $\mathrm{B}$ and $\mathrm{C}$ rectal carcinoma: A report of the NSABP clinical trials. Ann Surg. 1986; 204: 480-9.
4. Isenberg J, Keller HW, Pichlmaier H. Middle and lower third rectum carcinoma: Sphincter saving or abdominoperineal resection? European Journal of Surg. Oncology 1995; 21(3): 265 -268.

5. Glattli A, Barras JP, Metzger U. Is there still a place for abdominoperineal resection of the rectum? European Journal of Surg Oncology. 1995; 21(1): 11-15.

6. Slanetz C, Herter F, Grinnell R. Anterior Resection v/s Abdominoperineal Resection for cancer of the rectum and rectosigmoid. The American Journal of Surgery. 1972; 123: $110-115$.

7. Williams NS, Johnston D. Quality of life after sphincter saving resection or abdominoperineal resection for low rectal cancer. Br J Surgery. 1982; 69: 613 -616.

8. Henrichsen, Christiansen. Prognostic staging of extraperitoneal rectal cancer. Dis Colon Rectum. 1989; 32: 214-218.

9. Dawson P, Blair S, Begent $S$ et al. The value of Radioimmunoguided Surgery in First and Second look laparotomy for colorectal cancer. Dis Colon rectum. 1991; 34: 217-222.

10. Rouanet P, Senesse P, Bouamrirene D, Toureille E et al. Anal sphincter reconstruction by dynamic graciloplasty after abdominoperineal resection for cancer. Dis Colon Rectum. 1999; 42(4): 451-456.

11. Fleshman JW, Wexner SD, Anvari M, Kodner J et al. Laparoscopic v/s open abdominoperineal resection for cancer. Dis of colon \& Rectum. 1999; 42(7): 930- 939.

12. Zaheer S, Pemberton JH, Farouk R, Dozois RR et al. Surgical treatment of Adenocarcinoma of the rectum. Ann Surg. 1998; 227(6): 800-811.

13. Luna - Perez, Rodriguez-Ramirez et al. Morbidity and mortality following abdominoperineal resection for low rectal adenocarcinoma. Revista de investigacion clinica. 2001; 53[5]: 388-395.

14. Rosen L, Veidenheimer MC, Collar JA, Corman ML. Mortality \& Morbidity patterns of recurrence after abdominoperineal resection for cancer of rectum. Dis colon Rectum. 1982; 25: 203.

15. Nissan A, Guillem J, Paty $P$ et al. Abdominoperineal resection for rectal cancer at a specialty centre. Dis colon rectum. 2001; 44: 27-36.

16. Fick T, Baeten et al. Recurrence and Survival after abdominoperineal and low anterior resection for rectal cancer without adjunctive therapy. Eur J Surg Oncol. 1990; 16: 105-8.

17. Dixon AR, Maxwell WA, Holmes JT. Carcinoma of the rectum: a 10-year experience. Br J Surg. 1991; 78(3): 308311. 